\title{
Light and Temperature Independently Influence Methoxypyrazine Content of Vitis vinifera (cv. Cabernet Sauvignon) Berries
}

\author{
Cassandra M. Plank ${ }^{1}$ \\ Department of Viticulture and Enology, University of California at Davis, 1 \\ Shields Avenue, Davis, CA 95616
}

\section{Edward W. Hellman and Thayne Montague \\ Texas Tech University and Texas A\&M University, Texas A\&M AgriLife Research \& Extension Center, Lubbock, TX 79403}

Additional index words. canopy management, shade, sunlight, light-emitting diode, growing degree days

\begin{abstract}
Methoxypyrazines (MPs) are fruit-derived extractable compounds that contribute to cultivar-specific aroma traits in wine, and greater concentrations can contribute to unpleasant vegetative aromas. Both light exposure and temperature have been reported to influence MP content in developing wine grapes, but individual effects of light and temperature are confounded. A novel method of manipulating light exposure with light-emitting diodes (LEDs) was used to impose light treatments with little or no effect on cluster temperature. Three treatments were imposed on developing fruit of Vitis vinifera (cv. Cabernet Sauvignon): 1) clusters exposed to direct sunlight, 2) clusters shaded by the grapevine canopy, and 3) clusters shaded by the canopy and exposed to supplemental LED light. Experiments were conducted over 3 years across pre- and postveraison periods of fruit development. A second experiment imposed the same light exposure treatments to ripening clusters on vines experiencing continual shoot growth during the postveraison period. Light exposure reduced 3-isobutyl-2-methoxypyrazine (IBMP) concentration of developing grape berries in the preveraison period independently of berry heating from solar radiation. Berry IBMP responded less to postveraison light levels, except on vines with active shoot growth, suggesting IBMP synthesis was continued during active vine growth but was suppressed by light. An inverse relationship of growing degree days (GDDs) with berry IBMP was observed, indicating high temperatures also reduce berry IBMP concentration. Response to temperature could result from either radiant heating of light-exposed clusters or from high ambient air temperature. Canopy management should consider the impact of both light and temperature on IBMP, and vine management practices should be adjusted appropriately to regional growing conditions and grape cultivars.
\end{abstract}

MPs are a class of aroma compounds responsible for vegetal aromas in fruit of some Vitis vinifera L. wine grape cultivars. MPs have been quantified in Grenache (López et al., 1999), Merlot (Sala et al., 2000), Cabernet Franc (Allen et al., 1994), and Cabernet Sauvignon (Bayonove et al., 1975). Sensory trials supplemented quantification in Carmenere (Belancic and Agosin, 2007) and Sauvignon blanc (Augustyn et al., 1982). Reciprocal grafting experiments demonstrated MPs or their precursors originate in berries, rather than being synthesized in

Received for publication 4 Oct. 2018. Accepted for publication 7 Dec. 2018.

This study was supported in part with funds provided by the Texas Department of Agriculture, Enology and Viticulture Extension and Research Grant Program.

We thank Keith Jenkins, Brent Pape, Yanmei Zhang, and Tony Harbuck for technical assistance. ${ }^{1}$ Corresponding author. E-mail: cassandra.m.plank@ gmail.com. developing grape berries would reduce MP concentration via this mechanism. Consequently, Sauvignon blanc clusters were exposed to increased sunlight through leaf removal treatments, resulting in decreased herbaceous aromas of corresponding wines (Allen et al., 1988; Arnold and Bledsoe, 1990). Subsequent research examined various methods of canopy manipulation to increase sunlight exposure of fruit in attempts to reduce MP content, including basal leaf removal (Scheiner et al., 2010), shoot thinning (Ryona et al., 2008), pruning (Allen and Lacey, 1993; Chapman et al., 2004a, 2004b), different trellis and training systems (Kotseridis et al., 1999; Sala et al., 2004b), combinations of training systems and canopy management treatments (Balda and Martinez de Toda, 2013), shadecloth (Koch et al., 2012; Sala et al., 2004b), and opaque boxes (Dunlevy et al., 2013a). Recent research suggests fruit light exposure may reduce MP accumulation through inhibition of biosynthesis (Koch et al., 2012; Ryona et al., 2010; Scheiner et al., 2010). Dunlevy et al. (2010, 2013a) demonstrated a methyltransferase gene was involved in MP biosynthesis and light-reduced expression and concentration of an IBMP precursor (Dunlevy et al., 2013a). As a result of the apparent effect of sunlight exposure on biosynthesis of MP, preveraison is considered the critical time to decrease accumulation of MPs (Koch et al., 2012; Ryona et al., 2008) whereas postveraison light exposure has been reported to have little effect on reducing final MP content of grapes (Koch et al., 2012; Ryona et al., 2008; Scheiner et al., 2010).

It seems clear from these studies that sunlight exposure on developing fruit decreases MP content, but the potential confounding effect of radiant heat from sunlight on MP content has not been examined. Both light exposure and temperature have been reported to influence MP content in developing wine grapes (Allen and Lacey, 1993; Koch et al., 2012; Noble et al., 1995; Ryona et al., 2008), however the individual effect of each factor is difficult to distinguish as a result of the heat generated by light absorbance, as noted by Ryona et al. (2008). It is generally recognized that sun-exposed fruit typically have greater berry temperatures compared with shaded clusters. Smart and Sinclair (1976) reported berry temperature increases linearly with sunlight exposure. Temperatures of sunlight-exposed clusters on the south side of east-west rows in the central San Joaquin Valley of California were generally 3 to $4{ }^{\circ} \mathrm{C}$ greater when compared with clusters on the north side of the row (Bergqvist et al., 2001). In eastern Washington, berry temperature of sunlight-exposed clusters was 4 to $13{ }^{\circ} \mathrm{C}$ greater than ambient air temperature and shaded cluster temperatures regardless of row aspect (Spayd et al., 2002). Their study found west-exposed clusters sometimes exceeded temperatures of $40{ }^{\circ} \mathrm{C}$. It is possible, therefore, that the reported association of reduced MP content with sunlight-exposed grape berries could be, at least in part, a result of temperature effects. 
Studies reporting effects of temperature on grape berry MP content have mostly involved broad comparisons of fruit or wines from regions or seasons with significant temperature differences (Allen and Lacey 1993; Falcão et al., 2007; Heymann and Noble, 1987; Lacey et al., 1988, 1991; Marais et al., 1999; Mendez-Costabel et al., 2013), all of which involved uncontrolled confounding factors of environment and vineyard management practices. Nevertheless, a trend is evident: MPs tend to be greater in fruit or wine from cooler growing regions and seasons (Allen and Lacey 1993; Falcão et al., 2007; Heymann and Noble, 1987; Lacey et al., 1991). Lower MP levels were observed in the warmest year of a 3-year field study on Cabernet Sauvignon fruit from a broad range of cluster light exposure treatments, and temperature effects on MP were examined in a companion study conducted in growth chambers (Koch et al., 2012). Two constant temperature regimes representing average daily temperatures for a warm and a cool growing region were imposed on potted Cabernet Sauvignon grapevines receiving either a low light (close to zero) treatment or a relatively high light $\left(500-600 \mu \mathrm{mol} \cdot \mathrm{m}^{-2} \cdot \mathrm{s}^{-1}\right)$ treatment. Significant differences in MP levels were only detected between fruit from the high-light/hightemperature and low-light/low-temperature treatments (Koch et al., 2012). Separation of light and temperature effects were achieved in a field study by Spayd et al. (2002), indicating regardless of cluster temperature, light had the greatest influence on anthocyanin levels in Merlot berries, but MP levels were not measured.

Greater fruit MP content has also been associated with abundant soil moisture availability (Mendez-Costabel et al., 2014; Qian et al., 2009; Sala et al., 2005) and conditions conducive to active vine growth, which leads to shading (Mendez-Costabel et al., 2013; Roujou de Boubée et al., 2002; Scheiner et al., 2012; Wilkinson et al., 2008). Carmenere was reported to have greater MPs in a season with late rainfall, which resulted in a second vegetative growth period, leading the authors to postulate that new growth promoted MP biosynthesis and transportation to berries (Belancic and Agosin, 2007). This explanation seems unlikely given subsequent reciprocal grafting experiments that demonstrated MPs are not translocated from vegetative tissues and are likely synthesized within grape berries (Koch et al., 2010).

To investigate light exposure effects on MP concentration of developing grape berries in the absence of radiant heat, small panels of LEDs were used to illuminate clusters that would otherwise be shaded from sunlight within the canopy. Shoot positioning was used to maintain cluster exposure to sunlight or shade in an experiment conducted across the pre- and postveraison periods of fruit development. A second experiment imposed similar treatments to ripening clusters on vines experiencing continual shoot growth during the postveraison period in response to supplemental irrigation. To elucidate light vs. temperature effects, at the end of each developmental period, berry IBMP levels for shaded clusters were compared with shaded clusters receiving supplemental light from LEDs.

\section{Materials and Methods}

Experiments were conducted at the Texas A\&M AgriLife Research and Extension Center, Lubbock, TX (lat. $33^{\circ} 41^{\prime} 33^{\prime \prime} \mathrm{N}$, long. $\left.101^{\circ} 49^{\prime} 17^{\prime \prime} \mathrm{W}\right)$ during the growing seasons of 2011, 2012, and 2013. Data vines were established on $V$. vinifera cv. Cabernet Sauvignon FPS 07 on $110 \mathrm{R}$ rootstock planted in 2008 at a $1.8 \times 3$-m vine-by-row spacing with north-south row orientation and experimental clusters on the west side. Vines were bilateral cordon-trained and spur-pruned to two buds. Canopies were managed in a sprawl configuration with cordons established at $\approx 90 \mathrm{~cm}$, with single foliage catch wires at $\approx 15 \mathrm{~cm}$ and $\approx 35 \mathrm{~cm}$ above the cordon. Weather data, including GDD accumulation and annual precipitation were collected from a weather station located at Lubbock Preston Smith International Airport, located $\approx 3 \mathrm{~km}$ from the vineyard block (Weather Underground, 2016).

A novel method of manipulating light levels in the field with LEDs was used to impose light exposure treatments with little or no effect on cluster temperature (Plank et al., 2016). Three treatments were imposed: 1) clusters exposed to direct sunlight, 2) clusters shaded by the grapevine canopy, and 3) clusters shaded by the canopy and exposed to supplemental LED light. Treat- ments were applied to one basalmost cluster per vine, with clusters selected for homogeneity among vines. Upper foliage wires were used to maintain the canopy around shadeand LED-treatment clusters, and to move shoots away from sun-exposed clusters throughout the growing season. Vines received standard vineyard management for the region, and light treatments were imposed at two stages: one cluster at preveraison (fruit set to veraison), which was harvested $50 \mathrm{~d}$ postanthesis; and one cluster postveraison (veraison to harvest), harvested at ${ }^{\circ} \mathrm{Brix}$ levels typical for commercial harvest parameters, with average ${ }^{\circ}$ Brix ranging from 23 to 24.6, $\mathrm{pH}$ between 3.4 and 3.9, and between 5.3 and $7.2 \mathrm{~g} \cdot \mathrm{L}^{-1}$ tartaric acid (TA). A second experiment was conducted to investigate the hypothesis of Belancic and Agosin (2007) that new growth promotes MP biosynthesis and transportation to berries. Cluster light exposure treatments were imposed during the postveraison period on vines receiving additional irrigation to encourage continuous shoot growth.

Preveraison and postveraison experiments. Treatments were assigned randomly to 45 vines among two adjacent rows of Cabernet Sauvignon, and each of three treatments was assigned randomly to 15 single-vine replicates. A single basal cluster per vine received the assigned light exposure treatment during the preveraison period imposed at fruit set. A second cluster on a different shoot of the same vine received the same light treatment during the postveraison period imposed at veraison. All fruit were harvested the same day.

Table 1. Growing degree-day (GDD) accumulation, annual precipitation, and phenology dates for Cabernet Sauvignon at Lubbock, TX, for 2011, 2012, and 2013.

\begin{tabular}{|c|c|c|c|c|c|c|}
\hline \multirow[b]{2}{*}{$\mathrm{Yr}$} & \multicolumn{3}{|c|}{$\operatorname{GDD}\left({ }^{\circ} \mathrm{C}\right)$} & \multirow{2}{*}{$\begin{array}{l}\text { Annual } \\
\text { precipitation } \\
(\mathrm{cm})\end{array}$} & \multirow{2}{*}{$\begin{array}{l}\text { Avg maximum } \\
\text { season wind } \\
\text { speed }\left(\mathrm{km} \cdot \mathrm{h}^{-1}\right)^{\mathrm{x}}\end{array}$} & \multirow{2}{*}{$\begin{array}{c}\text { Phenology } \\
\text { dates } \\
\text { (veraison) }\end{array}$} \\
\hline & Preveraison $^{\mathrm{z}}$ & Postveraison $^{\mathrm{y}}$ & Season $^{x}$ & & & \\
\hline 2011 & $1,511.4$ & $1,098.0$ & $3,042.7$ & 14.88 & 39.9 & 15 July \\
\hline 2012 & $1,369.7$ & 656.2 & $2,859.2$ & 29.03 & 38.0 & 10 July \\
\hline 2013 & $1,445.8$ & 692.5 & $2,699.1$ & 32.03 & 39.1 & 25 July \\
\hline
\end{tabular}

${ }^{\mathrm{z}}$ Cumulative 1 Apr. to veraison.

${ }^{\mathrm{y}}$ Cumulative veraison to harvest

${ }^{\mathrm{x}}$ Cumulative 1 Apr. to 31 Oct.

Table 2. Photosynthetically active radiation $(P A R)$ received by Cabernet Sauvignon grape clusters exposed to either direct sunlight, shaded by canopy, or shaded by canopy with supplemental light-emitting diode (LED) light. Exposure occurred in preveraison (fruit set to $50 \mathrm{~d}$ postanthesis), postveraison (veraison to harvest), and postveraison under a continuous shoot growth during 3 study years in Lubbock, TX.

\begin{tabular}{llrrr}
\hline & & \multicolumn{3}{c}{ Mean $P A R\left(\mu \mathrm{mol} \cdot \mathrm{m}^{-2} \cdot \mathrm{s}^{-1}\right)^{\mathrm{z}}$} \\
\cline { 3 - 5 } Expt. $^{\mathrm{x}}$ & Treatment & 2011 & 2012 & 2013 \\
\hline Preveraison & Shade & $47 \mathrm{c}$ & $29 \mathrm{~b}$ & $20 \mathrm{c}$ \\
& Shade + LED & $1,479 \mathrm{~b}$ & $1,874 \mathrm{a}$ & $1,988 \mathrm{~b}$ \\
& Sun & $1,901 \mathrm{a}$ & $1,888 \mathrm{a}$ & $2,107 \mathrm{a}$ \\
Postveraison & Shade & $31 \mathrm{~b}$ & $28 \mathrm{c}$ & $109 \mathrm{c}$ \\
& Shade + LED & $1,806 \mathrm{a}$ & $1,759 \mathrm{~b}$ & $1,682 \mathrm{~b}$ \\
& Sun & $1,851 \mathrm{a}$ & $1,920 \mathrm{a}$ & $1,844 \mathrm{a}$ \\
Continuous growth & Shade & $36 \mathrm{~b}$ & $21 \mathrm{~b}$ & $88 \mathrm{c}$ \\
& Shade + LED & $1,877 \mathrm{a}$ & $1,829 \mathrm{a}$ & $1,741 \mathrm{~b}$ \\
& Sun & $1,814 \mathrm{a}$ & $1,813 \mathrm{a}$ & $1,929 \mathrm{a}$ \\
\hline
\end{tabular}

${ }^{\mathrm{z}}$ Means within columns followed by same letter are not significantly different at $P<0.05 ; \mathrm{n}=15$ (least significant difference test).

${ }^{y}$ Shade = cluster shaded by canopy; Shade + LED = cluster shaded by canopy with supplemental LED light; Sun = clusters exposed to full sunlight.

${ }^{\mathrm{x}}$ Data for all experiments analyzed independently. 
LED panels were constructed as described in Plank et al. (2016). Cluster and canopy temperature were monitored continuously in 30-min intervals with Watchdog Temperature and Relative Humidity sensors and dataloggers (1000 Series Micro Stations; Spectrum Technologies, Aurora, IL). Interior cluster temperature was considered a good representation of all berries in a cluster; therefore, a fine-wire thermistor (Watchdog Temperature Micro Sensor, Spectrum Technologies) was threaded into the center of the cluster, secured with tying tape, and connected to a datalogger. The datalogger also recorded temperature of the air within the canopy, which served as ambient canopy temperature. Dataloggers were placed in radiation shields and secured to the $T$ post between vines. Data were downloaded from the units using Spec 9 Basic software (version 9.02, Spectrum Technologies). Photosynthetically active radiation $(P A R)$ exposure was measured weekly for each cluster with a Fieldscout 1400 Light Sensor Reader (Spectrum Technologies) on cloudless days during the solar noon period (1000-1400 HR). The $P A R$ sensor was oriented to each cluster such that the sensor measured incident solar radiation or LED light.

Continuous growth experiment. Vines of Cabernet Sauvignon FPS 07 on 110R rootstock planted in 2006 in another location of the same vineyard were used for the continuous shoot growth study. Spacing and trellis/ training configurations were the same as described previously. Continuous growth experiment vines were arranged in a randomized complete block design with four blocks. Each block consisted of a five-vine block, of which three data vines were selected randomly. Each of the three previously described cluster exposure treatments were assigned randomly to one vine per block, with a single basal cluster per vine receiving the assigned light treatment. A second drip irrigation line was installed in each block to provide supplemental water applications of $2.5 \mathrm{~cm} /$ week throughout the growing season. Light exposure treatments were imposed beginning at veraison and continued until berries were harvested at ${ }^{\circ} \mathrm{Brix}$ levels
(22.1-23.2) typical for commercial harvest. Cluster temperature and $P A R$ were measured for each treatment, as described for the preand postveraison experiment. Shoot length was measured weekly from veraison to harvest on five shoots on the east side of experimental vines, and averaged among all shoots per block.

Total soluble solids, $p H$, TA, and berry weight. Clusters for MP analysis were too small to include in total soluble solids (TSS) content; therefore, other fruit was collected from the experimental vines to examine TA, $\mathrm{pH}$, and TSS content on a single harvest date each year. TSS content was determined using a temperature-compensating digital refractometer (Atago PR-32; Bellevue, WA). Juice $\mathrm{pH}$ and TA were determined using an autotitrator (Metrohm 862 Compact Titrosampler; Herisau, Switzerland). TA was determined with $0.1 \mathrm{~N} \mathrm{NaOH}$ to an endpoint of $\mathrm{pH}$ 8.2.

Fruit analysis. Fruit samples were prepared using methods adapted from Du et al. (2010). Fruit were frozen and stored at $-18^{\circ} \mathrm{C}$ until sample preparation, when they were thawed in a refrigerator overnight. Twentyfive grams of berries were removed from stems for each sample cluster. To inhibit enzymatic action, an equal weight of distilled water $(25 \mathrm{~g})$ and $1 \%(\mathrm{w} / \mathrm{w})$ calcium chloride (final concentration) was added to thawed berries. Samples were pureed with a Tissuemax Tissumizer \#SIT-1810 (Tekmar Co., Cincinnati, $\mathrm{OH}$ ) then placed in $50-\mathrm{mL}$ centrifuge tubes and centrifuged in an Eppendorf 5804R centrifuge (Eppendorf, Hauppauge, $\mathrm{NY}$ ) for $20 \mathrm{~min}$. Supernatant was filtered through Whatman's No. 1 (particle retention, $>11 \mu \mathrm{m}$ ) followed by VWR 413 filter paper (particle retention, $>5 \mu \mathrm{m}$ ) (VWR, Radnor, PA). Supernatants from each sample were divided into triplicates of $10-\mathrm{mL}$ aliquots and sealed in $20-\mathrm{mL}$ amber headspace vials. To perform stir-bar sorptive extraction, a $10-\mathrm{mm}$ polydimethylsiloxane stir bar (Gerstel, Inc., Germany), conditioned according to the manufacturer's directions, was added to each headspace vial. Because 2-ethoxy-3ethylpyrazine (EEP) is similar to the target compounds but not found in grapes (Flamini and Traldi, 2010; Hartmann et al., 2002;
Sala et al., 2004a), EEP served as the internal standard. For each vial, $10 \mu \mathrm{L}$ of $10 \mathrm{mg} / \mathrm{L}$ EEP (Pyrazine Specialties, Ellenwood, GA) diluted in ethanol was added. Vials were stirred for $35 \mathrm{~min}$ to absorb volatiles, then stir bars were removed, rinsed lightly with ultrapure water, and dried with a lint-free tissue.

Gas chromatography/mass spectrometry was used for quantification. IBMP and 3isopropyl-2-methoxypyrazine (IPMP) were quantified concomitantly with one stir bar. Each stir bar was placed in an Agilent 51813316 single taper, deactivated splitless liner. The liner was then inserted into a splitless inlet and desorbed at a temperature of $200{ }^{\circ} \mathrm{C}$ in an Agilent Tech 7890A GC system (Agilent Technologies, Inc., Santa Clara, CA). Compound separation was achieved with an HP 5 MS column $(30 \mathrm{~m} \times 0.25 \mathrm{~mm}$ i.d., 0.25 $\mu \mathrm{m}$ thickness). The temperature program was set as follows: initial hold at $40{ }^{\circ} \mathrm{C}$ for $5 \mathrm{~min}$, followed by $4{ }^{\circ} \mathrm{C} / \mathrm{min}$ ramp to $124{ }^{\circ} \mathrm{C}$ with no hold, then $20^{\circ} \mathrm{C} / \mathrm{min}$ ramp to $220^{\circ} \mathrm{C}$ with a 5 -min hold. Helium served as the carrier gas, with a flow rate of $0.5 \mathrm{~mL} / \mathrm{min}$. Total runtime of the method was $35.8 \mathrm{~min}$. Because retention times of compounds of interest eluted toward the end of the run, a 17-min solvent delay was used. Ion source temperature was $230{ }^{\circ} \mathrm{C}$.

Quantification was accomplished with an Agilent Tech 5975C VL MSD with TripleAxis Detector. Enhanced ChemStation E02.01.1177 software from Agilent Technologies, Inc., was used to visualize the output from the mass spectrometer. Quantification of MPs was based on peak area, and identification of compounds was achieved through select ion monitoring. Values were doubled as a result of 2-fold dilution by the addition of water to grape must (homogenized berry tissue). Selected mass channels were $\mathrm{m} / \mathrm{z}=$ 124 (quantifier), 151, and 166 for IBMP; $m / z=124,137$ (quantifier), and 152 for IPMP; and $m / z=123$ (quantifier), 124, and 152 for EEP (Flamini and Traldi, 2010). A six-point standard curve with concentrations ranging from 4 to $1000 \mathrm{ng} / \mathrm{L}(\mathrm{n}=6)$ was prepared for IBMP and IPMP in ultrapure water, resulting in $R^{2}=0.9990$ for IPMP and

Table 3. Temperature of grape clusters exposed to direct sunlight, shaded by the canopy, or shaded clusters exposed to supplemental LED light in preveraison or postveraison. Temperatures are shown for morning (0800 HR), midday (1300 HR), and late afternoon (1700 HR) for 2011, 2012, and 2013 in Lubbock, TX.

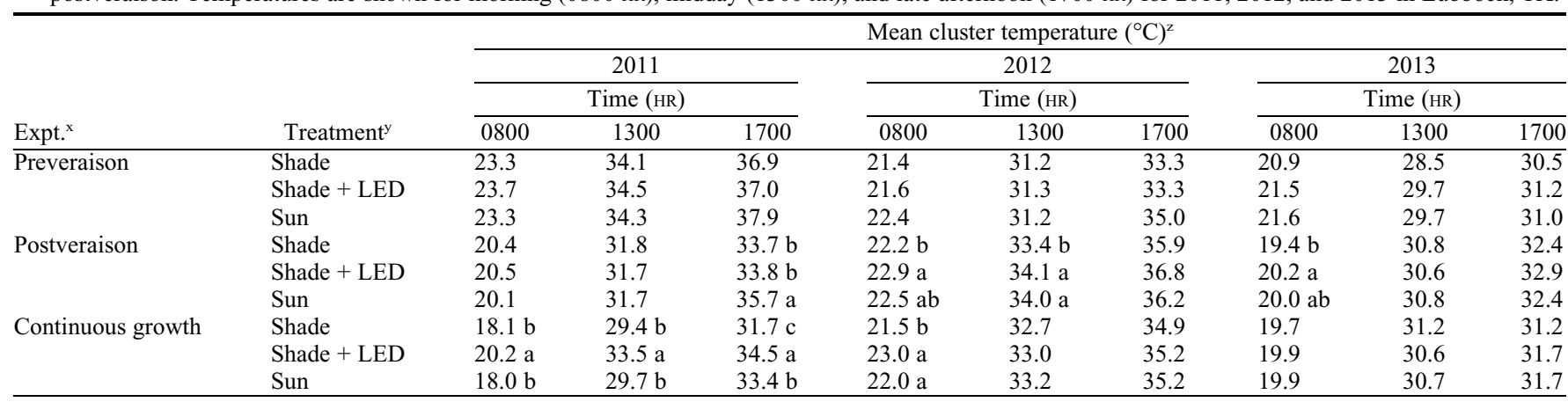

\footnotetext{
${ }^{\mathrm{z}}$ Means within columns followed by the same letter are not significantly different at $P<0.05 ; \mathrm{n}=15$ (least significant difference test).

${ }^{\mathrm{y}}$ Shade = cluster shaded by canopy; Shade + LED = cluster shaded by canopy with supplemental LED light; Sun = clusters exposed to full sunlight.

${ }^{\mathrm{x}}$ Experiments analyzed independently.
} 
$R^{2}=0.9999$ for IBMP. Standards of known concentration were used to determine accuracy and reproducibility of MP determinations. Limit of detection was determined to be less than $1.9 \mathrm{ng} / \mathrm{L}$ for IBMP, within range of previously reported values of 0.2 to $2 \mathrm{ng} / \mathrm{L}$ (Alberts et al., 2009). Peak area was used to determine concentration of MPs in the juice solution.

Statistics. Analysis of variance $(\alpha=0.05)$ was performed using SAS version 9.3 (SAS Institute, Cary, NC). Proc GLM was used to analyze $P A R$, cluster temperature, and MP concentration in fruit. The $P A R$ model used the mean of three point measurements taken each sampling day for each treatment. Cluster temperatures were examined at three times during the day: 0800, 1300, and 1700 HR. Means were separated using least significant difference.

\section{Results}

Weather conditions at the experimental vineyard site varied over the 3 years of this study, with 2011 experiencing exceptionally high GDD accumulation, particularly postveraison, and record-low precipitation (Table 1). Postveraison GDD accumulation in 2011 was $67.3 \%$ and $58.6 \%$ greater than 2012 and 2013, respectively. This is attributable in part to the greater number of days between veraison and harvest in 2011, but total GDD accumulation for the season (1 Apr.-31 Oct.) was also greater in 2011 than subsequent years, and $6.4 \%$ to $12.7 \%$ greater than 2012 and 2013, respectively.

Pre- and postveraison experiment. Light interception by developing grape clusters was substantially greater for canopy-shaded clusters illuminated with LED (Shade + LED) compared with canopy-shaded clusters without supplemental lighting (Shade) during all experimental periods (Table 2). Incident PAR on clusters of Shade + LED treatments was consistently similar to sunlight exposed clusters (Sun), and exceeded that of the Shade treatment by an average factor of 55, and ranged from 15 to 99 times greater across all experimental periods.

Mean cluster temperature at three times of day for all experiments is reported in Table 3. No difference in cluster temperatures were found among treatments over 3 years in the preveraison experiment, although Shade clusters had slightly lower temperatures than one or both light treatments in the postveraison experiment in a few instances.

Fruit IBMP concentrations responded to cluster light exposure treatments during both preveraison and postveraison periods, although the response was greater and more consistent in preveraison treatments (Fig. 1). Preveraison Sun and Shade + LED treatments resulted in lower IBMP concentrations in fruit at the mid-development stage compared with Shade treatments in both 2012 and 2013. Shade treatment in 2012 had $\approx 43 \%$ and $15 \%$ greater IBMP than Shade + LED and Sun treatments, respectively. In 2013, preveraison Shade had more than $50 \%$ greater IBMP
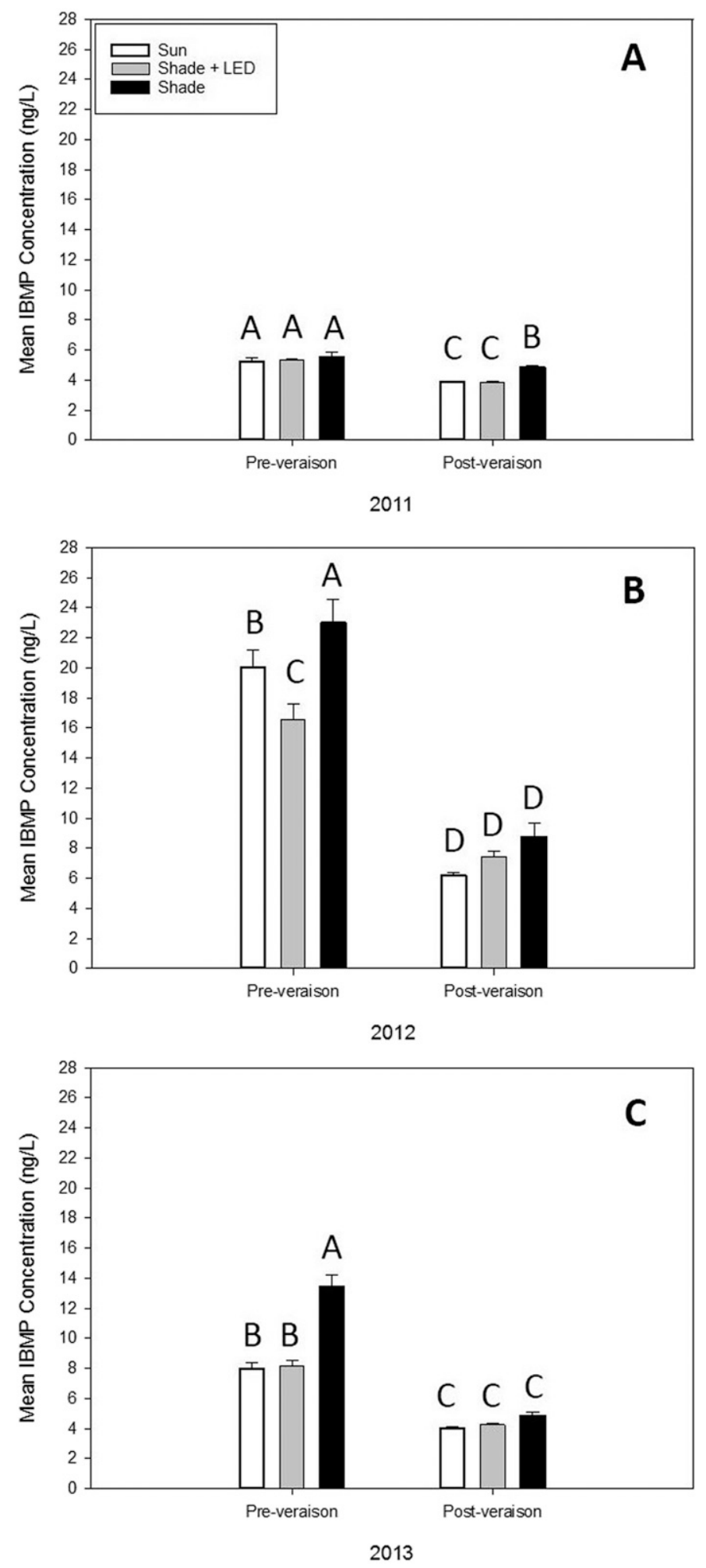

Fig. 1. Mean 3-isobutyl-2-methoxypyrazine (IBMP) concentration of Cabernet Sauvignon berry solutions with 1:1 dilution for clusters receiving light treatments during pre- and postveraison periods in (A) 2011, (B) 2012, and (C) 2013. Different letters within a year indicate significant treatment effects (Proc GLM; $\alpha=0.05, \mathrm{n}=15, P \leq 0.05)$. Error bars based on SEM. LED = light-emitting diode.

than both the Shade + LED and Sun treatments. All 2012 preveraison treatments and the 2013 preveraison Shade treatment produced fruit at mid development with IBMP exceeding the reported (Sala et al., 2005) sensory threshold range for red wine of 10 to $16 \mathrm{ng} / \mathrm{L}$. Regardless of light treatment and year, fruit IBMP concentration decreased between the mid-development stage (preveraison treatment period) and mature fruit (postveraison treatment period), with low final concentrations in the range of 4 to 8 $\mathrm{ng} / \mathrm{L}$. Light treatments imposed postveraison resulted in slightly lower IBMP in the Sun 
and Shade + LED treatments compared with the Shade treatment in 2011, with a similar trend in 2012 and 2013. In all cases, IBMP levels of mature fruit subjected to light treatments postveraison were less than the sensory threshold for red wine. IPMP was not detected in fruit from either treatment period.

Continuous growth experiment. Active shoot growth from veraison to harvest was observed in all 3 years for blocks receiving weekly supplemental irrigation (Fig. 2), although total shoot length and growth rate were considerably less for all vines during the exceptionally warm and dry year of 2011. As with the preveraison and postveraison experiments, differential light treatments were imposed (Table 2), which resulted in few differences in cluster temperature among treatments (Table 3). Higher cluster temperature was observed for the Shade + LED treatments compared with Sun and Shade treatments in 2011 only.

Vines with continuous shoot growth produced mature fruit with low final concentrations of IBMP very similar to levels found in postveraison fruit from the other experiment-in the range of 4 to $6 \mathrm{ng} / \mathrm{L}$. Light treatments imposed on actively growing vines during the postveraison period induced a response in IBMP concentration of mature fruit. The Sun and Shade + LED treatments had reduced mature berry IBMP concentration in 2 of 3 years compared with the Shade treatment (Fig. 3). Nevertheless, all light exposure treatments under continuous shoot growth produced mature fruit with IBMP levels less than the sensory threshold, and IPMP was not detected-results that are consistent with levels found in clusters postveraison in the other experiment.

\section{Discussion}

Light exposure reduced IBMP concentration of developing grape berries preveraison in concurrence with previous reports (Dunlevy et al., 2013b; Koch et al., 2012; Ryona et al., 2008; Scheiner et al., 2010), and our results demonstrate the light effect is independent of berry heating from solar radiation. The light response was quantified previously by Koch et al. (2012), who reported an inverse relationship of IBMP to light intensity from $0 \%$ to about $50 \%$ full sunlight with no further response as light increased, but their shaded clusters appeared to experience lower temperatures than exposed clusters. Both Ryona et al. (2008) and Dunlevy et al. (2013b) noted their methodology could not rule out lack of solar radiation in their shade treatments could have resulted in less radiant heating compared with sunlightexposed berries. Our experiment was designed to eliminate radiant heat as a source of increased berry temperature, demonstrating light independently reduces IBMP concentration of fruit during the preveraison period.

Nevertheless, there appears to be an effect of ambient air temperature on IBMP, as our results also corroborate previous observations of an inverse correlation of GDD
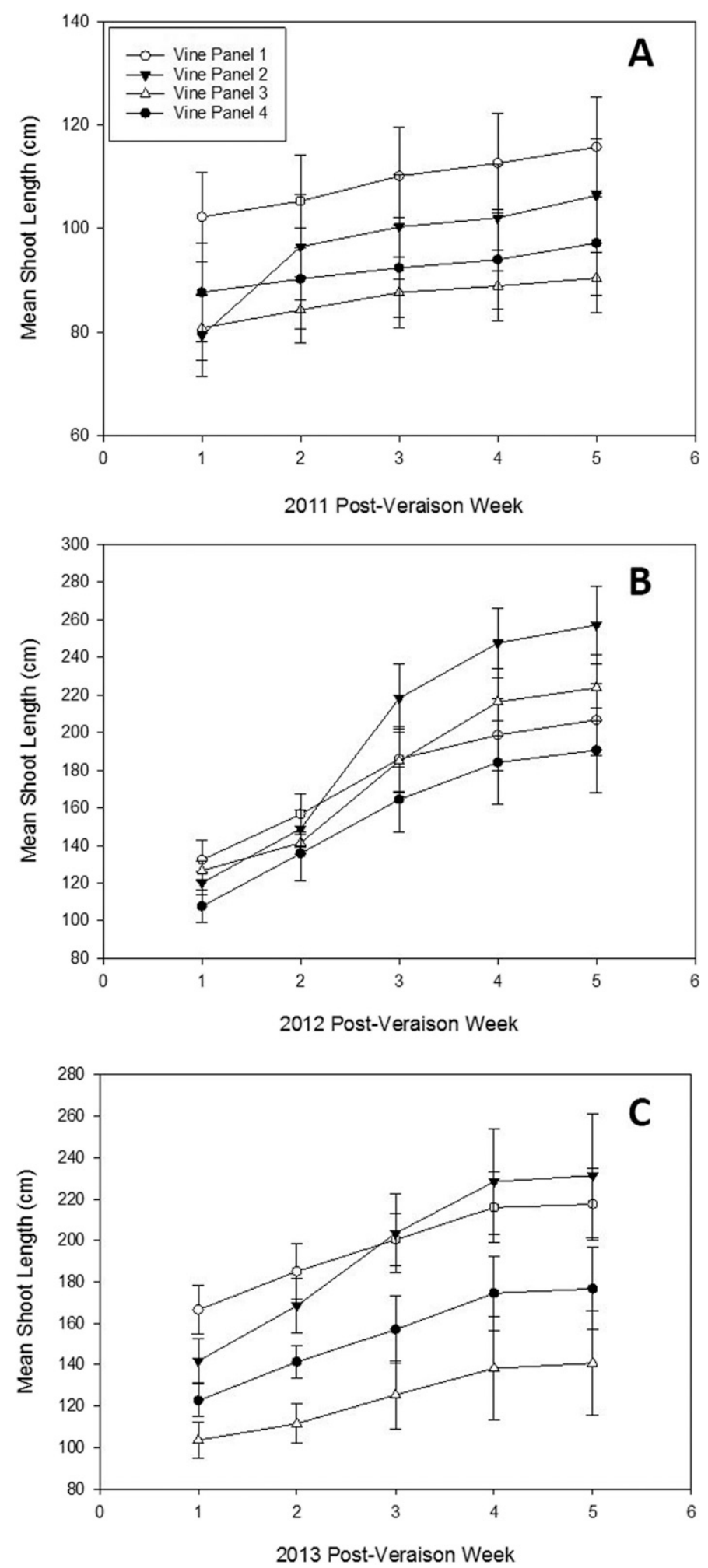

Fig. 2. Mean shoot length recorded for five shoots within each five-vine block from postveraison to harvest. Blocks received $2.5 \mathrm{~cm} /$ week supplemental irrigation across each growing season over 3 years: (A) 2011, (B) 2012, and (C) 2013.

accumulation with IBMP of mature fruit (Alberts et al., 2009; Allen and Lacey 1993; Allen et al., 1994; Falcão et al., 2007; Heymann and Noble, 1987; Koch et al., 2012; Lacey et al., 1991). The greatest IBMP levels were found in fruit at the middevelopment stage and at harvest under the lowest GDD in 2012, whereas the lowest
IBMP levels occurred in the warmest year (2011). Overall growing season temperatures were also likely responsible for low berry IBMP concentrations at harvest for all light treatments in all years. The Texas High Plains is a warm growing region (Hellman et al., 2011) and GDD accumulations ranged from 2699 to $3043^{\circ} \mathrm{C}$ during the period of our 


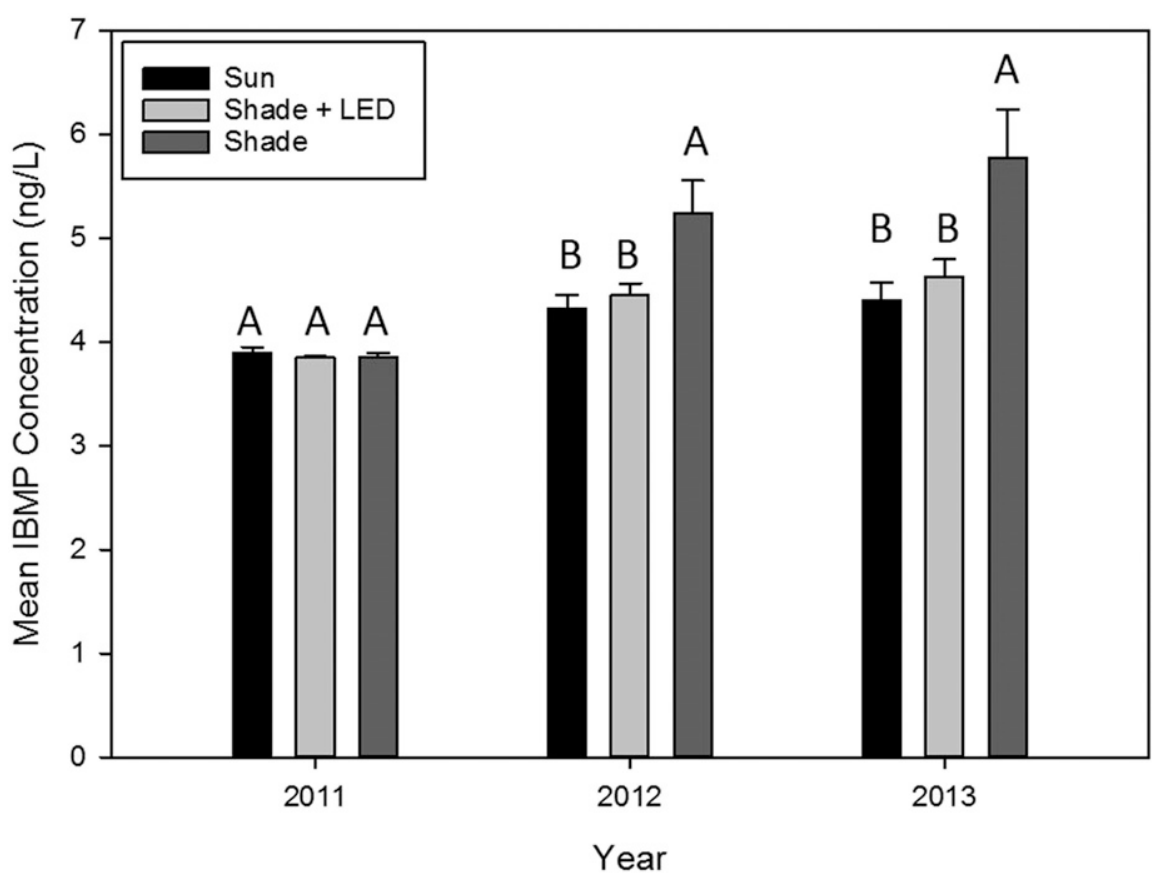

Fig. 3. Mean 3-isobutyl-2-methoxypyrazine (IBMP) concentration in Cabernet Sauvignon berry solutions with 1:1 dilution for clusters receiving light treatments in the postveraison period under continuous shoot growth conditions induced by supplemental irrigation. Different letters within each year indicate significant treatment effects (Proc GLM; $\alpha=0.05, \mathrm{n}=15, P \leq 0.05$ ). Error bars based on SEM. LED = light-emitting diode.

study. Similarly, Koch et al. (2012) reported IBMP levels were lowest and less than detection levels in the warmest year of their study. Cluster temperature may have been influenced by wind speed. Average wind speed for the season (1 Apr.-31 Oct.) ranged from 38.0 to $39.9 \mathrm{~km} \cdot \mathrm{h}^{-1}$ (Table 1). As noted in Plank et al. (2016), wind conditions in the field may have dissipated heat across the LED panels, and could have affected cluster temperatures of sun- and shade-exposed clusters, dissipating cluster temperature and decreasing the temperature difference of clusters across treatments.

Thus, both light and temperature affect IBMP before veraison, but it is unclear whether the mechanisms are similar. Dunlevy et al. (2013b) demonstrated preveraison sunlight exposure reduces berry IBMP accumulation through decreased expression of the methyltransferase gene $V v O M T 3$ responsible for the final step in MP biosynthesis. Because their study could not distinguish temperature effects, it is possible greater ambient temperatures also suppress VvOMT3 expression. It has also been suggested IBMP biosynthesis and degradation occur simultaneously during the preveraison period (Scheiner et al., 2010), and it seems plausible degradation is enhanced by increased air temperature.

Berry IBMP concentration decreased from mid development (preveraison) to harvest, following the pattern reported by numerous authors (Allen et al., 1996; Dunlevy et al., 2013b; Koch et al., 2012; Roujou de Boubée et al., 2000; Ryona et al., 2008; Scheiner et al., 2010). By harvest, berry IBMP was low for all treatments, less than the sensory threshold levels for red wine, with only a slight and inconsistent ( 1 of 3 years) postveraison response to light levels. These results confirm reduced (Dunlevy et al., 2013b; Sala et al., 2004b) or no response (Koch et al., 2012; Ryona et al., 2008 ) to postveraison light exposure on berry IBMP at harvest. Because expression of the $V v O M T 3$ gene involved in IBMP synthesis was reported to be much lower postveraison (Dunlevy et al., 2013b), the suppression response to light treatments would be expected to be less effective, and Dunlevy et al. (2013b) suggested degradation or metabolism of IBMP is responsible for the large declines in IBMP during the grape ripening period. It seems likely high ambient air temperatures, as described earlier, experienced during the postveraison period, could enhance degradation or metabolism of IBMP. Whether degradation is enzymatic or nonenzymatic has yet to be determined (Lei et al., 2018).

A more consistent response to postveraison cluster light exposure occurred in the continuous growth experiment, where shaded treatments had greater berry IBMP content in 2 of 3 years. Similarity of these results to our clusters harvested preveraison suggests berries on vines in a state of continuous growth continue to synthesize IBMP, and thus respond to the gene suppression effect of light treatments, but $V v O M T 3$ expression would need to be verified under such conditions. This mechanism would help explain reported association of berry IBMP in actively growing or highly vigorous vines (Belancic and Agosin, 2007; MendezCostabel et al., 2013; Roujou de Boubée et al., 2002), in addition to cluster shading resulting from a dense canopy. Despite the

response to cluster light exposure of continuously growing vines, harvested fruit had low IBMP levels, less than the threshold level at harvest, suggesting degradation or metabolism mechanisms possibly influenced by high ambient air temperatures.

Light exposure of clusters reduces IBMP concentration in developing grape berries independently of radiant heat. Response to light is greatest during the preveraison period, or when vines are actively growing postveraison, and appears to be related to suppression of $V v O M T 3$ expression during IBMP biosynthesis. High temperatures also reduce berry IBMP concentration, which could result from either radiant heating of light-exposed clusters or from high ambient air temperature. Vineyard managers should consider the impact of both light and temperature on IBMP and adjust canopy management practices appropriately to match regional growing conditions and grape cultivars. In cool climates prone to greater IBMP, hedging or leaf removal on both the morning and afternoon sides of the canopy could enhance sunlight exposure and radiant heat on developing clusters. It is likely that berry MP levels can also be minimized by vineyard management practices, resulting in limited shoot growth postveraison.

\section{Literature Cited}

Alberts, P., M.A. Stander, S.O. Paul, and A. de Villiers. 2009. Survey of 3-alkyl-2-methoxypyrazine content of South African Sauvignon blanc wines using a novel LC-APCI-MS/MS method. J. Agr. Food Chem. 57:9347-9355.

Allen, M.S. and M.J. Lacey. 1993. Methoxypyrazine grape flavor: Influence of climate, cultivar and viticulture. Wein-Wiss. 48:211-213.

Allen, M.S., M.J. Lacey, and S. Boyd. 1994 Determination of methoxypyrazines in red wines by stable isotope dilution gas-chromatography mass-spectrometry. J. Agr. Food Chem. 42: 1734-1738

Allen, M.S., M.J. Lacey, and S. Boyd. 1996 Methoxypyrazines: New insights into their biosynthesis and occurrence. Proc. Fourth Intl. Symp. Cool Climate Viticult. Enol. V36-V39.

Allen, M.S., M.J. Lacey, R.L.N. Harris, and W.V. Brown. 1988. Sauvignon blanc varietal aroma. Austr. Grapegr. Winem. 292:51-56.

Arnold, R.A. and A.M. Bledsoe. 1990. The effect of various leaf removal treatments on the aroma and flavor of Sauvignon blanc wine. Amer. J. Enol. Viticult. 41:74-76.

Augustyn, O.P.H., A. Rapp, and C.J. Van Wyk 1982. Some volatile aroma components of Vitis vinifera L. cv. Sauvignon blanc. S. Afr. J. Enol. Viticult. 3:53-60.

Balda, P. and F. Martinez de Toda. 2013. Effects of clusters exposure levels on pyrazines content in red wines of Vitis vinifera cv. Maturana Tinta de Navarrette. Cienc. Vitivinic. 28:702-706.

Bayonove, C., R. Cordonnier, and P. Dubois. 1975 Étude d'une fraction caractéristique de l'arôme du raisin de la variété Cabernet-Sauvignon: Mise en évidence de la 2-méthoxy-3-isobutylpyrazine. C.R. Hebd. Acad. Sci. 2812:75-78.

Belancic, A. and E. Agosin. 2007. Methoxypyrazines in grapes and wines of Vitis vinifera cv. Carmenere. Amer. J. Enol. Viticult. 58:462-469.

Bergqvist, J., N. Dokoozlian, and N. Ebisuda. 2001. Sunlight exposure and temperature effects on berry growth and composition of 
Cabernet Sauvignon and Grenache in the Central San Joaquin Valley of California. Amer. J. Enol. Viticult. 52:1-7.

Chapman, D.M., M.A. Matthews, and J. Guinard. 2004a. Sensory attributes of Cabernet Sauvignon wines made from vines with different crop yields. Amer. J. Enol. Viticult. 55:325334.

Chapman, D.M., J.H. Thorngate, M.A. Matthews, J.X. Guinard, and S.E. Ebeler. 2004b. Yield effects on 2-methoxy-3-isobutylpyrazine concentration in Cabernet Sauvignon using a solid phase microextraction gas chromatography/ mass spectrometry method. J. Agr. Food Chem. 52:5431-5435.

Du, X., A. Kumianta, M. McDaniel, C.E. Finn, and M.C. Qian. 2010. Flavour profiling of 'Marion' and thornless blackberries by instrumental and sensory analysis. Food Chem. 121:1080-1088.

Dunlevy, J.D., E.G. Dennis, K.L. Soole, M.V. Perkins, C. Davies, and P.K. Boss. 2013a. A methyltransferase essential for the methoxypyrazine-derived flavor of wine. Plant J. 75:606-617.

Dunlevy, J.D., K.L. Soole, M.V. Perkins, E.G. Dennis, R.A. Keyzers, C.M. Kalua, and P.K. Boss. 2010. Two $O$-methyltransferases involved in the biosynthesis of methoxypyrazines: Grapederived aroma compounds important to wine flavour. Plant Mol. Biol. 74:77-89.

Dunlevy, J.D., K.L. Soole, M.V. Perkins, E.L. Nicholson, S.M. Maffei, and P.K. Boss. 2013b. Determining the methoxypyrazine biosynthesis variables affected by light exposure and crop level in Cabernet Sauvignon. Amer. J. Enol. Viticult. 64:450-458.

Falcão, L.D., G. de Revel, M.C. Perello, A. Moutsiou, M.C. Zanus, and M.T. BordignonLuiz. 2007. A survey of seasonal temperature and vineyard altitude influences on 2-methoxy3-isobutylpyrazine, C13-norisoprenoids, and the sensory profile of Brazilian Cabernet Sauvignon wines. J. Agr. Food Chem. 59:54315435.

Flamini, R. and P. Traldi. 2010. Grape aroma compounds: Terpenes, C13-norisoprenoids, benzene compounds, and 3-alkyl-2-methoxypyrazines, p. 97-116. In: D.M. Desiderio and N.M.M. Nibbering (eds.). Mass spectrometry in grape and wine chemistry. Wiley, Hoboken, NJ.

Hartmann, P.J., H.M. McNair, and B.W. Zoecklein. 2002. Measurement of 3-alkyl-2methoxypyrazine by headspace solid-phase microextraction in spiked model wines. Amer. J. Enol. Viticult. 53:285-288.

Hein, K., S.E. Ebeler, and H. Heymann. 2009. Perception of fruity and vegetative aromas in red wine. J. Sens. Stud. 24:441-455.

Hellman, E.W., E.A. Takow, M.D. Tchakerian, and R.N. Coulson. 2011. Geology and wine 13: Geographic information system characterization of four appellations in West Texas, USA. Geosci. Can. 38:6-20.

Heymann, H. and A.C. Noble. 1987. Descriptive analysis of commercial Cabernet Sauvignon wines from California. Amer. J. Enol. Viticult. 38:41-44.

Heymann, H., A.C. Noble, and R.B. Boulton. 1986. Analysis of methoxypyrazines in Wines: 1 . Development of a quantitative procedure. Amer. Chem. S. 34:268-271.
Koch, A., C.L. Doyle, M.A. Matthews, L.E. Williams, and S.E. Ebeler. 2010. 2-Methoxy3-isobutylpyrazine in grape berries and its dependence on genotype. Phytochemistry 71:2190-2198.

Koch, A., S.E. Ebeler, L.E. Williams, and M.A. Matthews. 2012. Fruit ripening in Vitis vinifera: Light intensity before and not during ripening determines the concentration of 2methoxy-3-isobutylpyrazine in Cabernet Sauvignon berries. Physiol. Plant. 45:275-285.

Kotseridis, Y., C. Anocibar-Beloqui, C. Bayonove, R.L. Baumes, and A. Bertrand. 1999. Effects of selected viticultural and enological factors on levels of 2-methoxy-3-isobutylpyrazine in wines. J. Intl. Sci. Vigne. Vin. 33:19-23.

Lacey, M.J., M.S. Allen, R.L.N. Harris, and W.V. Brown. 1991. Methoxypyrazines in Sauvignon blanc grapes and wine. Amer. J. Enol. Viticult. 42:103-108.

Lacey, M.J., W.V. Brown, M.S. Allen, and R.L.N. Harris. 1988. Alkyl methoxypyrazines and Sauvignon Blanc character. Proc. Second Intl. Cool Climate Viticult. Oenology Symp. 344345 .

Lei, Y., S. Xie, X. Guan, C. Song, Z. Zhang, and J. Meng. 2018. Methoxypyrazines biosynthesis and metabolism in grape: A review. Food Chem. 245:1141-1147.

López, R., V. Ferreira, P. Hernández, and J.F. Cacho. 1999. Identification of impact odorants of young red wines made with Merlot, Cabernet Sauvignon and Grenache grape varieties: A comparative study. J. Sci. Food Agr. 79:14611467.

Marais, J., J.J. Hunter, and P.D. Haasbroek. 1999. Effect of canopy microclimate, season and region on Sauvignon blanc grape composition and wine quality. S. Afr. J. Enol. Viticult. 20:19-30.

Mendez-Costabel, M.P., K.L. Wilkinson, S.E.P. Bastian, C. Jordans, M. McCarthy, C.M. Ford, and N. Dokoozlian. 2014. Effect of increased irrigation and additional nitrogen fertilization on the concentration of green aroma compounds in Vitis vinifera L. Merlot fruit and wine. Aust. J. Grape Wine Res. 20:80-90.

Mendez-Costabel, M.P., K.L. Wilkinson, S.E.P. Bastian, M. McCarthy, C.M. Ford, and N. Dokoozlian. 2013. Seasonal and regional variation of green aroma compounds in commercial vineyard of Vitis vinifera L. Merlot in California. Amer. J. Enol. Viticult. 64:430-436.

Noble, A.C., D.L. Elliott-Fisk, and M.S. Allen. 1995. Vegetative flavor and methoxypyrazines in Cabernet Sauvignon, p. 226-234. In: R.L. Rousoff and M.M. Leahy (eds.). Fruit flavors: Biogenesis, characterization, and authentication. Amer. Chem. Soc., Washington, DC.

Plank, C.M., E.W. Hellman, and T. Montague. 2016. Light-emitting diodes as supplemental lighting in viticulture field research. Amer. J. Enol. Viticult. 67:251-256.

Qian, M.C., Y. Fang, and K. Shellie. 2009. Volatile composition of Merlot wine from different vine water status. J. Agr. Food Chem. 57:74597463.

Roujou de Boubée, D., A.M. Cumsille, M. Pons, and D. Dubourdieu. 2002. Location of 2methoxy-3-isobutylpyrazine in Cabernet Sauvignon grape bunches and its extractability during vinification. Amer. J. Enol. Viticult. 53:1-5.

Roujou de Boubée, D., C. Van Leeuwen, and D. Dubourdieu. 2000. Organoleptic impact of 2-methoxy-3-isobutylpyrazine on red Bordeaux and Loire wines: Effect of environmental conditions on concentrations in grapes during ripening. J. Agr. Food Chem. 48:4830-4834

Ryona, I., S. Leclerc, and G.L. Sacks. 2010 Correlation of 3-isobutyl-2-methoxypyrazine to 3-isobutyl-2-hydroxypyrazine during maturation of bell pepper (Capsicum annuum) and wine grapes (Vitis vinifera). J. Agr. Food Chem. 58:9723-9730.

Ryona, I., B.S. Pan, D.S. Intrigliolo, A.N. Lakso, and G.L. Sacks. 2008. Effects of cluster light exposure on 3-isobutyl-2-methoxypyrazine accumulation and degradation patterns in red wine grapes (Vitis vinifera L. cv. Cabernet Franc). J. Agr. Food Chem. 56:10838-10846.

Sala, C., O. Busta, and J. Guasch. 2004a. Determination of 3-alkyl-2-methoxypyrazines in grapes, musts and wines: A review. J. Agr. Food Chem. 52:3492-3497.

Sala, C., O. Busta, J. Guasch, and F. Zamora. $2004 \mathrm{~b}$. Influence of vine training and sunlight exposure on the 3-alkyl-2-methoxypyrazines content in musts and wines from the Vitis vinifera variety Cabernet Sauvignon. J. Agr. Food Chem. 52:3492-3497.

Sala, C., O. Busta, J. Guasch, and F. Zamora. 2005. Contents of 3-alkyl-2-methoxypyrazines in musts and wines from Vitis vinifera variety Cabernet Sauvignon: Influence of irrigation and plantation density. J. Sci. Food Agr. 85:1131-1136.

Sala, C., M. Mestres, M.P. Marti, O. Busto, and J. Guasch. 2000. Headspace solid-phase microextraction method for determining 3-alkyl-2methoxypyrazines in musts by means of polydimethylsiloxane-divinylbenzene fibres. J. Chromatogr. 880:93-99.

Scheiner, J.J., G.L. Sacks, B. Pan, S. Ennahli, L. Tarlton, A. Wise, S.D. Lerch, and J.E. VandenHeuvel. 2010. Impact of severity and timing of basal leaf removal on 3-isobutyl-2methoxypyrazine concentrations in red wine grapes. Amer. J. Enol. Viticult. 61:358-364.

Scheiner, J.J., J.E. Vanden-Heuvel, B. Pan, and G.L. Sacks. 2012. Modeling impacts of viticultural and environmental factors on 3-isobutyl2-methoxypyrazine in Cabernet Franc grapes. Amer. J. Enol. Viticult. 63:94-105.

Smart, R.E. and T.E. Sinclair. 1976. Solar heating of grape berries and other spherical fruits. Agr. Meteorol. 17:241-259.

Spayd, S.E., J.M. Tarara, D.L. Mee, and J.C. Ferguson. 2002. Separation of sunlight and temperature effects on the composition of Vitis vinifera cv. Merlot berries. Amer. J. Enol. Viticult. 53:171-182.

Weather Underground. 2016. Lubbock International Station, Lubbock Preston Smith International Airport Lubbock, TX. 3 Feb. 2016. $<$ https://www.wunderground.com/history/ monthly/us/tx/lubbock/KLBB/>.

Wilkinson, K.L., U.J. Kennedy, K.J. Pierce, and M.R. Gibberd. 2008. Reducing green characters in Cabernet Sauvignon. Proc. Thirteenth Austral. Wine Ind. Tech. Conf. 193-196. 